\title{
A Mobilização de Resistência das Mulheres Negras na Computação e Tecnologias
}

\author{
Mory Márcia de Oliveira Lobo ${ }^{1}$, Karen da Silva Figueiredo ${ }^{12}$, Cristiano Maciel $^{12}$ \\ Programa de Pós-Graduação em Educação, Instituto de Educação - Universidade \\ Federal do Mato Grosso (UFMT), Cuiabá, Mato Grosso, Brasil ${ }^{1}$ \\ Instituto de Computação - Universidade Federal do Mato Grosso (UFMT), Cuiabá, \\ Mato Grosso, Brasil ${ }^{2}$ \\ morymarcia@hotmail.com, karen@ic.ufmt.br, cmaciel@ufmt.br
}

\begin{abstract}
This article presents a literature review essay that discusses the insertion of black women in Computer Science and Technologies in a social context of racism and sexism. Besides, it aims to present resistance strategies of black women in the area, especially in Brazil.
\end{abstract}

Resumo. Este artigo apresenta um ensaio bibliográfico que busca empreender o percurso de inserção de mulheres negras na computação e tecnologias, em um contexto social de segregação sexista e racial. Ainda, visa apresentar estratégias de resistência das mulheres negras na área, especialmente no cenário brasileiro.

\section{Introdução}

A atual configuração social do século XXI é fruto de transformações históricas de grande repercussão e mudanças expressivas no comportamento social da mulher contemporânea. A tão chamada sociedade da informação trouxe em sua bagagem, rompimentos estruturais que caracterizaram também, mudanças comportamentais nas relações de produção de conhecimento e tecnologias, ressignificando os lugares dos sujeitos nesse processo. Algumas áreas do conhecimento foram atribuídas como domínio masculino, tendo como exemplo a computação, campo historicamente dominado por homens brancos [Charleston et al. 2014]. Apesar das mulheres, como parte da sociedade contemporânea consumirem tecnologia diariamente, percebe-se que a elas foram limitados os caminhos da produção tecnológica. As mulheres representam menos de $20 \%$ dos profissionais da área, sendo apenas um terço destas mulheres negras [CRA et al. 2012].

Pensar na mulher e negra como objeto de pesquisa empreende novos desafios sobre temas cada vez mais complexos,. Neste sentido, surgem perguntas sobre questões importantes para a compreensão de fenômenos contemporâneos e consequentemente formulações abertas a contestações principalmente nos campos de pouca compreensão das ciências. Desta forma, o objetivo desse artigo é propor um ensaio bibliográfico sobre a inserção da mulher negra na computação e tecnologias (sessão 2) e apresentar estratégias de resistência das mulheres negras na área (sessão 3).

\section{Perspectivas teóricas}

De acordo com Silva (2017), áreas de estudos de gênero sobre a mulher negra cresceram e nos dotaram do passado que é extremamente essencial para a construção da 
identidade e para a própria questão da cidadania. A crítica a sociedade capitalista e a cultura de massas implica inclusive na questão de gênero e nos leva seguinte a indagação: como a mulher negra em um contexto social de segregação chega à produção tecnológica? A chegada da era tecnológica e digital ocasionou inseguranças no campo feminino pelo próprio histórico da mulher na sociedade a partir do momento em que lidar com a tecnologia exigiria mudanças significativas em adquirir novas habilidades e conhecimentos, novas formas de se relacionar e comunicar com outras pessoas. Nesta era, as pessoas são "livres" para pensar em seu projeto de vida, sua identidade, levando-os à condição da incerteza [Bauman 1998].

Para a mulher negra que historicamente é oriunda de classes subalternas, a utilização das tecnologias rompeu fronteiras para novas formas de lidar com novos conhecimentos em uma dimensão social. Kozinets (2014) ressalta a necessidade de compreendermos que a tecnologia não determina a cultura, mas, são codeterminantes e coconstrutivas, isso quer dizer que temos nossa cultura definida em padrões sociais e a moldamos pela tecnologia. Muito se tem perscrutado nas últimas décadas sobre a mobilização de mulheres negras no mercado de trabalho com o uso de tecnologias a partir do final do século XX. O impacto dessas inserções resultou, segundo Silva (2017), em uma mobilização de resistência que poderá implicar diretamente na desconstrução de discursos racializados e sexistas, partindo para mudanças que abrem espaços para o processo de produção tecnológica pela mulher negra.

Hall (2015) postula que essas mudanças fragmentam paisagens culturais de classe, gênero, sexualidade, etnia, raça e nacionalidade que no passado pareciam apresentar solidez. É relevante compreender que as mudanças decorrentes do advento da era tecnológica e que nortearam acontecimentos de reconfigurações processuais. Assim, novos suportes surgiram estruturando outras formas de pensar e ver o mundo em que, novos elementos surgem para a releitura da mulher negra brasileira e a formalização de fatos importantes ganham novas roupagens, novas interpretações e novas identidades.

A partir dessa ótica, é possível localizar no Brasil fatores históricos que sofreram influência significativa resultante do advento da era tecnológica como a inserção da mulher negra no mercado de produção e que vem ganhando visibilidade mesmo que pareça lenta mas que reconfigura uma nova consciência no respeito a diversidade.

De acordo com o Portal Baobá ${ }^{1}$, temos um número pequeno, mas importante de mulheres negras representadas por suas ideias e criações nas ciências, tecnologias e engenharias em um percurso expressivo para a inclusão na produção. A participação das mulheres negras na computação ainda é pequena, somando apenas $4 \%$ entre as fundadoras de startups de tecnologia comandadas por mulheres, e apenas 10 as mulheres negras que a Escola Politécnica da USP formou em 120 anos $^{2}$.

Os avanços considerados neste trabalho se atêm a todo um processo histórico de luta afirmativa e imagética referenciada à mulher negra que denotam a emergência de uma leitura sofisticada e propícia para a era tecnológica que consiga implementar um grau de qualidade necessária a uma classe ainda marginalizada para tempos de mal-estar

\footnotetext{
${ }^{1} \mathrm{http}: / /$ baoba.org.br/tem-mulher-negra-fazendo-tecnologia-e-inovacao-sim/

$2 \mathrm{http} / / /$ folha.uol.com.br/cotidiano/2017/02/1855107-aluna-negra-e-da-periferia-supera-preconceitos-paraestudar-na-poli.shtml?cmpid=compfb, http://fortune.com/2016/02/22/just-4-of-female-led-startups-arerun-by-black-women-im-one-of-them/
} 
e que utiliza dessas novas tecnologias como forma de resistência [Hooks 2015]. São essas complexidades de olhares diferenciados e voláteis, de leitura crítica própria para este tempo líquido e fugaz em que novos códigos e novas técnicas desafiam o modo convencional de ver o mundo e interpretá-lo [Bauman 1998].

\section{Mulheres Negras na Computação e Tecnologias}

Considerando o percurso, ainda que inicial da mulher negra como produtora de tecnologia, é possível que as discussões de gênero pelo acesso à computação funcionem como ponte de acesso para compreender as novas demandas identitárias no mercado de trabalho. Fica evidente a necessidade de entender melhor esse grupo sub-representado dentro da computação - um campo que necessita urgentemente de mais trabalhadores qualificados [Charleston et al. 2014].

Diversas entidades sociais e técnicas da computação reconhecem que as mulheres negras enfrentam desafios únicos, tais como isolamento, falta de confiança e sobrecarga, seja no ambiente acadêmico ou na indústria; e propõem algumas estratégias de sucesso para sobrepor tais problemas como a formação de redes de mentoria e apoio para mulheres negras na tecnologia; a divulgação de role models e o reconhecimento da diversidade cultural na produção tecnológica [CRA et al. 2012]. Assim, emergem iniciativas no Brasil e no exterior a fim de colocarem em prática tais estratégias. Algumas iniciativas internacionais ${ }^{3}$ de maior impacto são a Black Women in Computing, Black Girls Code e os eventos Black Tech Women e Black Women Talk Tech. No cenário nacional, ainda tímido, é possível encontrar as seguintes iniciativas ${ }^{4}$ :

- InfoPreta: empresa brasileira localizada em São Paulo, com visão social criada em 2015 exclusivamente por mulheres negras. Entre suas missões estão o impulsionamento de mulheres (negras e de outras minorias) para a área de exatas e ajudar a conservar o meio ambiente com o descarte correto dos eletrônicos e outros materiais. A InfoPreta oferece serviços tecnológicos de manutenção e reciclagem de computadores e aparelhos eletrônicos em geral, que são doados para mulheres periféricas. Também, a iniciativa oferece palestras e cursos de tecnologia, inovação e empreendedorismo com foco em relações étnico-raciais, gênero e diversidade para mulheres. A empresa possui parceria com a Microsoft Brasil e recentemente foi classificada para representar o Brasil no G20 em Berlim.

- Minas Programam: projeto paulista que visa desconstruir a noção de que os homens estão mais aptos a programar que as mulheres, por meio do compartilhamento de conhecimentos técnicos e políticos com mulheres. O projeto promove palestras e cursos para mulheres que também trabalham questões raciais como o "Meetup Preto", "Preta \& Acadêmica" e "WordPretas". O projeto conta com a parceria de empresas da área de computação como a ThoughtWorks e realiza por meio de mídias a divulgação de histórias de mulheres negras na área de TI a fim de estimular mais mulheres negras a seguirem a área.

- PretaLab: iniciativa do Olabi Makerspace com apoio da Fundação Ford que

\footnotetext{
${ }^{3}$ http://blackwomenincomputing.org/, https://anitab.org/systers/systers-communities/, www.blackgirlscode.com/, http://blacktechwomen.strikingly.com/, www.blackwomentalktech.com/ ${ }^{4}$ www.facebook.com/InfoPreta, www.facebook.com/minasprogramam/, http://pretalab.com/, www.facebook.com/meninasdigitaisBA
} 
acredita no protagonismo das meninas e mulheres negras e indígenas nos campos da inovação e tecnologia como forma de reduzir as desigualdades sociais do país. Tem como objetivo realizar um levantamento para coletar as histórias e desafios das mulheres negras e indígenas que atuam ou se interessam por tecnologias com um mapa colaborativo, tornando visíveis essas trajetórias e estimulando que outras mulheres considerem o universo da computação como uma possibilidade, ampliando o espaço e a representatividade destas mulheres na área.

- Meninas Digitais Regional Bahia: projeto parceiro do Programa Meninas Digitais da Sociedade Brasileira de Computação $(\mathrm{SBC})^{5}$ que tem como foco a inclusão de meninas e mulheres negras e/ou oriundas da rede de ensino público como forma de oportunizar para essas minorias o contato com a ciência e tecnologia. O projeto realiza palestras e oficinas em escolas públicas e também pesquisas sobre mulheres negras na ciência e computação [Mattos et al. 2016].

\section{Considerações Finais}

Os campos da inovação e da computação preparam a mulher negra, segregada e marginalizada, para atuar como produtora de tecnologia aberta a pluralidade cultural e geradora de conhecimentos que quebram paradigmas dominadores. As iniciativas socias, de mercado, pesquisa e extensão apresentadas neste ensaio apontam para o avanço das discussões na área e sinalizam caminhos para um trabalho coletivo em prol da equidade de gênero interseccional da computação, que incluam também os atravessamentos de raça e classe social.

\section{Referências}

Bauman, Z. (2007) "Vida Líquida", Rio de Janeiro: Zahar.

Charleston, L. J. et al. (2014) "Navigating underrepresented STEM spaces: Experiences of black women in U.S. computing science higher education programs who actualize success", In: Journal of Diversity in Higher Education, 7(3), p.166-176.

CRA (Computing Research Association) et al. (2012) "Academic Women of Color in Computing: A Testimony on the Issues and Possible Solutions", Relatório Técnico, Disponível em: http://www.oswego.edu/Documents/STEM/6.20_Computer _Research_Association.pdf acesso em 02 de abril de 2018.

Hall, S. (2015) “A identidade cultural na pós-modernidade”, 12a ed., Editora Lamparina.

Hooks, B. (2015) "Mulheres negras: Moldando a teoria Feminista.", In: Revista Brasileira de Ciência Política, nº16. Brasília, p.193-210.

Kozinets, R. V. (2014) "Netnografia: Realizando Pesquisa Etnográfica online”, Porto Alegre: Penso.

Matos, E. S. et al. (2016) "Sobre a trajetória de professoras negras na pós-graduação em Ciência da Computação: alguns resultados preliminares", In: Anais do Women in Information Technology (WIT 2016), SBC.

Silva, T. P. (2017) “Tics: A resistência de Mulheres Negras”, In: VI Seminário de Pesquisa em Ciência da Informação do PPGCI 2017, Universidade de São Paulo.

\footnotetext{
${ }^{5} \mathrm{http}: / /$ meninasdigitais.sbc.org.br/
} 